\title{
Pengukuran Batimetri Untuk Perencanaan Pengerukan Kolam Pelabuhan Peti Kemas Belawan Sumatera Utara
}

\author{
Syakinah Maghfirah Ayu ${ }^{1 *}$, Agus Anugroho Dwi Suryo P $^{1}$, Petrus Subardjo ${ }^{1}$, Sugeng Widada ${ }^{1}$ \\ dan Purwanto 1 \\ ${ }^{I}$ Departemen Oseanografi, Fakultas Perikanan dan Ilmu Kelautan, Universitas Diponegoro Jl. Prof. Sudarto, \\ SH Tembalang Tlp. / Fax. (024)7474698 Semarang 50275 \\ *Email : syakinahmaghfiraayu@gmail.com
}

\begin{abstract}
Abstrak
Kapal kandas kerap terjadi di Kolam Pelabuhan Peti Kemas Belawan diakibatkan adanya pendangkalan. Pendangkalan akibat inputan sedimen dari Muara Sungai Belawan membuat kedalaman tidak sesuai dengan draft minimum kapal. Hal ini menghambat aktivitas bongkar muat sehingga diperlukan perawatan kolam pelabuhan dengan cara pengerukan. Tujuan dilakukannya penelitian ini adalah untuk mengetahui kondisi kedalaman sebenarnya/eksisting dengan mengukur batimetri agar diketahui volume pengerukan penambahan kedalaman sesuai syarat aman draft kapal. Materi pada penelitian ini meliputi kedalaman eksisting, pasang surut, dan data draft kapal. Metode studi kasus diterapkan pada penelitian ini karena permasalahan yang dikaji menghasilkan hasil penelitian yang hanya dapat digunakan di lokasi tersebut. Hasil yang diperoleh dari penelitian ini adalah kedalaman eksisting yang berkisar antara $-3,70 \mathrm{~m}$ hingga $-10,5 \mathrm{~m}$. Berdasarkan hasil tersebut apabila disesuaikan dengan syarat aman kapal pada kolam pelabuhan yaitu -11 m, terjadi pendangkalan sehingga perlu dilakukan pengerukan. Setelah itu dihitung volume pendangkalan yang dikeruk berdasarkan desain kedalaman, slope, penambahan siltation rate menggunakan metode Grading dengan TIN (Triangulated Irregular Network) oleh perangkat lunak AutoCAD Civil 3D 2016. Total nilai volume pengerukan sedimen yang harus dikeruk sebesar 96.064,034 $\mathrm{m}^{3}$ agar kolam pelabuhan dapat dilalui kapal secara aman.
\end{abstract}

Kata kunci : Pelabuhan, Pengerukan, Survei Hidrografi, Singlebeam Echosounder

\begin{abstract}
Shipwrecks often occur in Belawan Container Port Pool due to silting. Siltation due to sediment input from the Belawan River Estuary makes depth not in accordance with the ship's minimum draft. This impedes loading and unloading activities so maintenance of the port pond is required by dredging. The purpose of this research is to find out the actual depth condition / existing by measuring bathymetry to know the dredging volume added depth according to the draft safety requirements of the ship. The material in this study includes the depth of the existing, tidal, and ship draft data. The case study method was applied in this study because the problem studied produced research results that could only be used in that location. The results obtained from this study are the existing depths ranging from $-3.70 \mathrm{~m}$ to $-10.5 \mathrm{~m}$. Based on these results, if adjusted to the safe conditions of ships in the port pool, namely $-11 \mathrm{~m}$, siltation occurs so dredging is necessary. After that, the shallow dredging volume is calculated based on the design of depth, slope, the addition of the siltation rate using the Grading method with TIN (Triangulated Irregular Network) by AutoCAD Civil 3D 2016. The total value of sediment dredging volume that must be dredged is 96,064,034 m3agar harbor ponds can be safely traversed by ships.
\end{abstract}

Keywords: Port, Dredging, Hydrographyc Survey, Singlebeam Echosounder

\section{PENDAHULUAN}

Pelabuhan merupakan tempat pemberhentian (terminal) kapal setelah melakukan pelayaran. Di pelabuhan ini, kapal melakukan berbagai kegiatan seperti menaik-turunkan penumpang, bongkar muat barang, pengisian bahan bakar, melakukan perbaikan, mengisi perbekalan dan sebagainya (Dwi et al, 
2017). Pelabuhan harus dilengkapi dengan fasilitas seperti pemecah gelombang, dermaga, kolam pelabuhan, peralatan tambatan, peralatan bongkar muat barang, gudang-gudang, halaman untuk menimbun barang, perkantoran baik untuk maskapai pelayaran dan pengelola pelabuhan, perlengkapan pengisian bahan bakar dan khususnya alur pelayaran (Triatmodjo, 1999). Yudianto et al (2014) menambahkan bahwa pelabuhan dikatakan beroperasi jika terdapat kapal yang berlabuh serta beraktifitas di pelabuhan. Tempat untuk berlabuh dan bersandarnya kapal dinamakan kolam pelabuhan.

Kolam pelabuhan termasuk pada proses pembangunan suatu pelabuhan yang tidak boleh ditinggal dan salah satu fasilitas paling penting. Kolam pelabuhan merupakan bagian dari perairan yang alami maupun buatan dari segi kedalaman dan lebar. Kolam pelabuhan harus mempunyai kedalaman dan lebar yang cukup atau sesuai dengan syarat aman kapal agar kapal dapat bersandar dengan aman. Hal tersebut mengharuskan tersedianya informasi kedalaman laut di area tersebut.

Menurut Poerbandono dan Djunarsjah (2005), informasi kedalaman laut diperoleh melalui survei batimetri. Hasil survei batimetri adalah proses penggambaran dasar perairan, dimulai dari pengukuran, pengolahan, hingga visualisasi dasar perairan. Defrimilsa (2003) menjelaskan bahwa batimetri memberikan informasi kedalaman berupa peta yang merupakan salah satu aspek yang sangat penting untuk beberapa kajian kegiatan sumberdaya kelautan, baik kedalaman di perairan dalam maupun perairan dangkal. Oleh karena itu, penentuan kedalaman kolam pelabuhan diperoleh dari hasil penggabungan peta batimetri dengan desain perencanaan dermaga meliputi draft kapal maksimum, laju sedimentasi, dan slope ( Wijayanto et al, 2014).

Pelabuhan Belawan merupakan salah satu pelabuhan yang sering bermasalah dengan kedalaman kolam pelabuhannya dikarenakan besarnya sedimen yang masuk ke kolam pelabuhan. Menurut Staff Direktorat Teknik PT. Pelindo 1 (2019), kerap terjadi kapal kandas di kolam sandar pelabuhan akibat adanya pendangkalan, tepatnya di Kolam pelabuhan Peti Kemas Pelabuhan Belawan yang memiliki aktivitas bongkar muat yang tinggi. Iskandar (2008) menambahkan bahwa lokasi tersebut rentan terhadap perpindahan material sedimen laut karena letaknya yang berada di muara Sungai Belawan yang banyak mengendapkan sedimen di sepanjang muara. Selain karena inputan sedimen dari Sungai Belawan, menyebabkan pendangkalan di alur masuk pelabuhan, didukung oleh pasang surut. Arus pasang surut membawa material sedimen dari muara Sungai Belawan sampai ke kolam pelabuhan pada saat pasang dan terendapkan pada saat surut. 


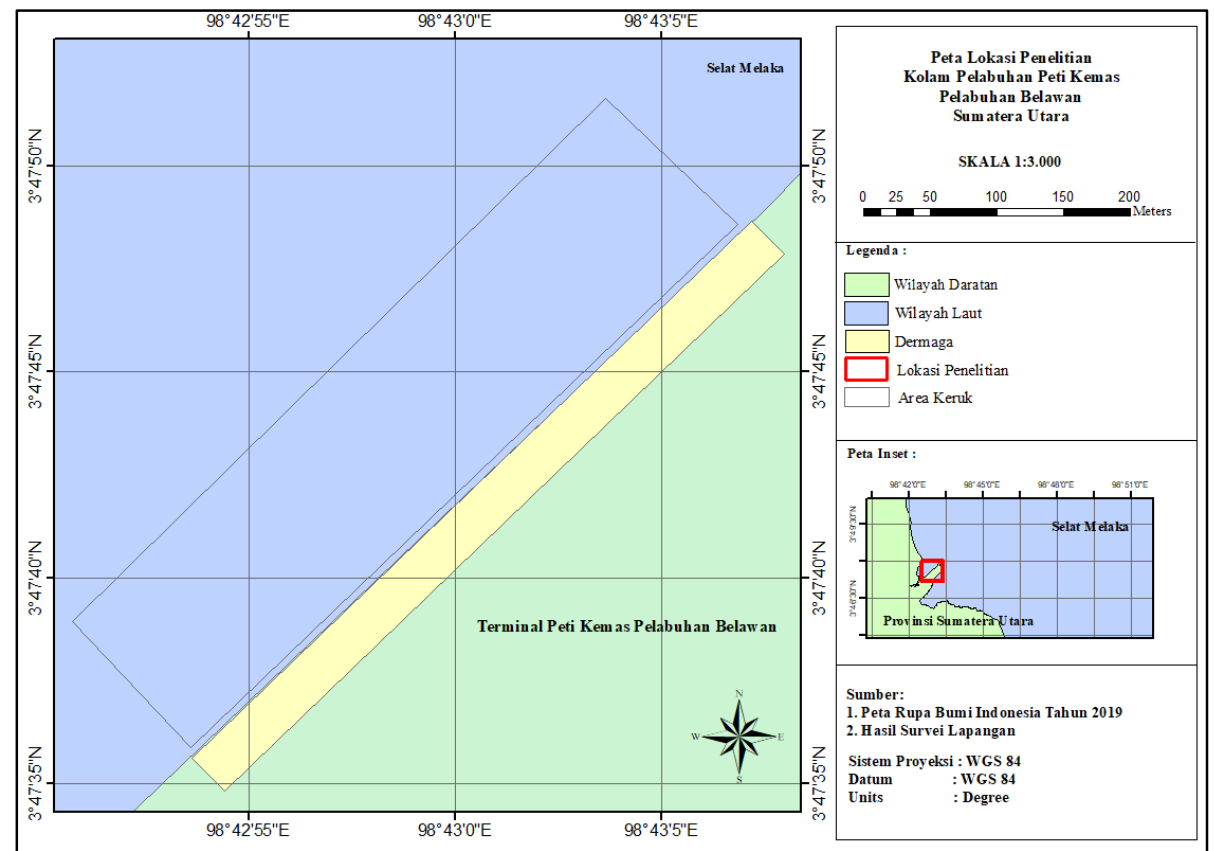

Gambar 1. Peta Lokasi Penelitian Pelabuhan Peti Kemas Belawan Sumatera Utara

Berdasarkan penelitian terdahulu dari Annisa (2017), menyatakan bahwa pendangkalan yang terjadi dapat diatasi dengan cara melakukan perawatan kolam pelabuhan yaitu dengan melakukan pengerukan. Penelitian serupa oleh Wijayanto et al (2017) menambahkan bahwa pengerukan kolam pelabuhan tidak terlepas dari pekerjaan survei pemetaan laut (survei batimetri). Survei batimetri memberikan gambaran tentang kondisi elevasi asli dari suatu kedalaman sebenarnya yang divisualisasikan menjadi peta batimetri. Hal ini perlu dipantau kedalamannya secara terus menerus agar diketahui volume sedimen yang menyebabkan pendangkalan. Sedimen itulah yang perlu dikeruk untuk mendapatkan kedalaman yang diinginkan. Peta batimetri berfungsi sebagai sumber data utama dalam menentukan desain pengerukan dan volume pengerukan pada kolam pelabuhan. Dalam rangka kelancaran aktivitas bongkar muat yang tinggi di Pelabuhan Peti Kemas Pelabuhan Belawan, maka penelitian ini perlu dilakukan. Penelitian ini dilakukan di Dermaga Peti Kemas Pelabuhan Belawan pada bulan September 2019 - Januari 2020 pada koordinat 98 42'50' - 98 $48^{\circ} 10^{\prime}$ 'BT dan $3^{0} 47^{\prime} 35^{\prime \prime}$ $3^{0} 47^{\prime} 50^{\prime \prime}$ (Gambar 1).

\section{MATERI DAN METODE}

\section{Materi Penelitian}

Materi yang digunakan dalam penelitian ini berupa data utama dan data pendukung. Adapun data utama diperoleh secara langsung melalui survey lapangan meliputi data uji barcheck, data batimetri, data pasang surut. Sedangkan data sekunder tidak diperoleh secara langsung melainkan hasil survey dari pihak lain antara lain data pasang surut bulan Januari 2019 dari Dinas Hidro-Oseanografi, data kecepatan arus Laporan Pelindo (2003), data desain keruk dari PT. Pelabuhan Indonesia I (Persero), dan data karakteristik kapal Pelabuhan Belawan 2018.

\section{Metode Penelitian}

Metode yang digunakan dalam penelitian ini adalah metode studi kasus. Metode ini menyajikan permasalahan secara rinci pada suatu kasus menggunakan data insitu sehingga hasil yang diperoleh 
hanya dapat digunakan pada lokasi tersebut (Surakhmad, 1980). Pada pelaksanaan penelitian ini meliputi survei lapangan, pengambilan data pasang surut, pengambilan data batimetri, analisis data batimetri, penentuan desain dan volume pengerukan dan penyusunan laporan.

\section{Metode Pengambilan Data}

Metode pengambilan data yang dilakukan agar terperoleh informasi kedalaman eksisting, sesuai dengan teknik survei hidrografi terkait survey batimetri diatur dalam S.44-IHO (IHO, 2005) dan menjadi SOP (Standard of Procedure) PT. Pelindo I. Untuk memperoleh informasi kedalaman, dilakukan pemeruman Singlebeam Echosounder Teledyne Odom Hydrotrack II dengan frekuensi $210 \mathrm{kHz}$. Sebelum pelaksanaan pemeruman (sounding) harus dibuat rencana lajur perum sesuai dengan panjang dermaga $600 \mathrm{~m}$ dengan lebar yang dibutuhkan yaitu $130 \mathrm{~m}$ menggunakan aplikasi MapSource. Data posisi pada survey diperoleh dari titik awal dan akhir dari tiap-tiap lajur sounding dicatat, untuk dijadikan acuan atau patokan motor boat sepanjang lajur sounding. Penentuan posisi pada survei harus direferensikan terhadap sistem koordinat geosentrik dengan datum World Geodetic System 84 (WGS84) menggunakan sistem DGPS (Differential Global Positioning System) pada alat GPS Garmin 585. Bersamaan dengan pemeruman dilakukan pengamatan pasang surut sesaat menggunakan Roll Meter. Pelabuhan Peti Kemas Belawan sudah diketahui nilai elevasi dermaganya, sehinga pengukuran pasang surut hanya dilakukan saat pengamatan berlangsung. Nilai elevasi dermaga yang sudah dijadikan LWS dijadikan patokan pada saat pengukuran permukaan air, dimana cara mengukur pasang surut adalah dengan memperoleh nilai jarak antara elevasi dermaga sampai permukaan air. Setiap 15 menit sekali titik 0 roll meter $m$ dijatuhkan dari tepi dermaga ke permukaan air lalu diukur elevasinya selama pemeruman dilakukan sehingga menghasilkan data mentah pasang surut sesaat.Data pasang surut sesaat ini digunakan untuk koreksi data batimetri, dikarenakan data batimetri yang diambil saat pemeruman dipengaruhi oleh tinggi pasang surut sesaat dilakukan pemeruman. Sehingga harus dikoreksi untuk mengetahui nilai kedalaman perairan sebenarnya.

\section{Metode Pengolahan Data}

\section{Pasang Surut}

Pengukuran lapangan yang memiliki titik 0 pada muka air, menghasilkan data mentah pasang surut yang merupakan jarak antara lantai dermaga ke muka air, sehingga untuk memproleh nilai elevasi pasang surut sebenarnya harus dikoreksi sesuai dengan nilai elevasi lantai dermaga yang sudah diikat pada benchmark memiliki nilai 3,73 m. Koreksi pasang surut ini disebut dengan Koreksi BM. Koreksi $\mathrm{BM}$ ini merupakan nilai pasang surut sebenarnya yang merupakan selisih nilai pengamatan pasang surut sesaat dengan tinggi dermaga yang menjadi acuan pengukuran permukaan air yang sudah terikat bench mark. Nilai selisih tersebut digunakan untuk perhitungan koreksi data kedalaman (batimetri)

\section{Batimetri}

Pengambilan data batimetri menghasilkan data tercatat pada alat Echosounder yakni jarak antara transducer dengan permukaan tanah pada perairan yang diukur kedalamannya.Transducer tersebut diletakkan di bagian tengah motor boat, di bawah permukaan air yang tidak terpengaruh oleh pasang surut. Oleh sebab itu diperlukan suatu koreksi kedalaman terhadap jarak transducer ke permukaan air dan koreksi kedalaman terhadap pasang-surut. Gambar 2. menampilkan sketsa definisi besaran-besaran yang terlihat dalam proses koreksi tersebut. 


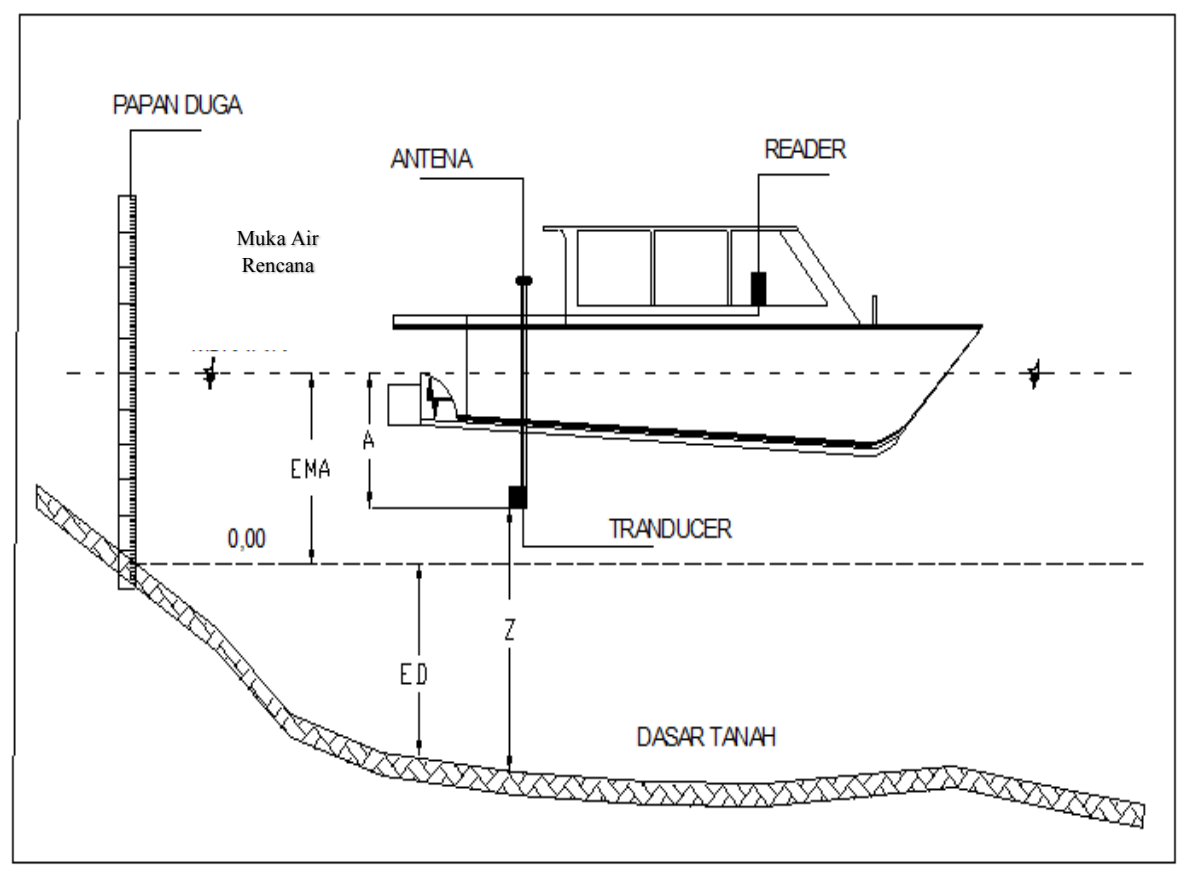

Gambar 2. Sketsa definisi besaran-besaran yang terlihat dalam koreksi kedalaman (Sumber : Laporan Survei PT. Pelindo 1)

Keterangan gambar :

\begin{tabular}{|c|c|}
\hline Z & $=$ kedalaman air hasil sounding (jarak dasar perairan ke \\
\hline & $=$ jarak transducer ke muka air \\
\hline & $=$ Elevasi dasar perairan terhadap muka surutan \\
\hline
\end{tabular}

Dari definisi-definisi diatas maka elevasi dasar perairan dihitung dari nol papan duga yang telah ditetapkan elevasi terhadap 0,00 LWS (ED) adalah :

$$
\mathrm{ED}=\mathrm{Z}+\mathrm{A}-\mathrm{EMA}
$$

Nilai-nilai kedalaman perairan terkoreksi (ED) ini kemudian diolah melalui perangkat lunak ArcGIS 10.4 dan AutoCAD CIVIL 3D 2016. Dengan menggunakan perangkat lunak ArcGIS 10.4 data kedalaman laut yang telah dikoreksi selanjutnya diinterpolasi dengan metode topo to raster yang ada dalam ArcToolbox. Topo to raster menginterpolasi terhadap nilai yang terdekat dengan titik yang terdekat untuk menampilkan garis garis kontur kedalaman. Lalu dibuat "section line" penampang melintang untuk melihat kondisi kedalaman pada area pengerukan. Sedangkan dengan menggunakan perangkat lunak AutoCAD CIVIL 3D 2016, nilai-nilai kedalaman perairan terkoreksi (ED) ini dinamakan data eksisting. Data eksisting ini merupakan model batimetri berupa persebaran dari titik titik fiks hasil pemeruman yang masing masing memiliki nilai elevasi.

\section{Desain Keruk}

Tahapan dalam penentuan desain keruk sudah diatur dalam Menteri Perhubungan No 3 Tahun 2013. meliputi:

1. Menentukan Kedalaman Kolam pelabuhan 
Tabel 1. Karakteristik Kapal Dermaga Peti Kemas PT. Pelabuhan Indonesia I (Persero) Tahun 2018 (Sumber: Survei Lapangan, 2019)

\begin{tabular}{ccc}
\hline No & Nama Kapal & $\begin{array}{c}\text { Draft } \\
(\mathrm{mLWS})\end{array}$ \\
\hline 1 & Morotai & $-9,8 \mathrm{~m}$ \\
2 & Wan Hai & $-9,6 \mathrm{~m}$ \\
3 & Horai Bridge & $-9,3 \mathrm{~m}$ \\
3 & Kota Hadiah & $-9,1 \mathrm{~m}$ \\
4 & Kestrel & $-8,4 \mathrm{~m}$ \\
5 & Sinar Bintan & $-8,2 \mathrm{~m}$ \\
6 & Sunshine Bandama & $-8.0 \mathrm{~m}$ \\
7 & Ctp Fortune & $-8,0 \mathrm{~m}$ \\
8 & Msc Maria Pia & $-7,8 \mathrm{~m}$ \\
9 & Cape Franklin & $-6,9 \mathrm{~m}$
\end{tabular}

Menurut Direkorat Jenderal Perhubungan Laut (2006), desain keruk di tentukan dengan draft kapal yang bersandar di dermaga dengan rumus,

Keterangan :

$$
d \geq 1,1 D
$$

$\mathrm{d}:$ desain kedalaman kolam

$\mathrm{D}:$ draft kapal maksimum

Berikut ini merupakan data karakteristik kapal dermaga peti kemas PT. Pelabuhan Indonesia III (Persero) cabang Belawan 2018 yang masuk dalam 9 angka draft kapal terbesar yang dapat dilihat pada Tabel 1.

2. Slope / Kemiringan Kolam pelabuhan

Slope / kemiringan kolam pelabuhan berfungsi untuk memberikan nilai keamanan pada kolam pelabuhan agar tidak terjadi longsor yang telah diatur dalam Menteri Perhubungan No 3 Tahun 2013 berupa klasifikasi kemiringan dapat dilihat melalui Tabel 2.

Tabel 2. Klasifikasi Kemiringan (Dirjen Perhubungan Laut, 2015)

\begin{tabular}{ccc}
\hline Klasifikasi & Jenis Tanah & Slope \\
\hline Tanah Lempung & Lumpur & $1: 3-5$ \\
& Lunak & $1: 2-3$ \\
& Sedang & $1: 1,5-2$ \\
& Keras & $1: 1-1,5$ \\
Pasir & Lunak & $1: 2-3$ \\
\hline
\end{tabular}




\begin{tabular}{|c|c|c|}
\hline & Sedang & $1: 1,5-2$ \\
\hline & Keras & $1: 1-1,5$ \\
\hline Kerikil & & $1: 1-1,5$ \\
\hline Batu karang & & 1 \\
\hline
\end{tabular}

\section{Siltation Rate}

Siltation rate adalah perkiraan pengendapan atau sedimentasi yang materialnya datang dari luar maupun dalam lokasi keruk yang terjadi pada saat pelaksanaan pengerukan.. Pada perangkat lunak AutoCAD Civil 3D 2016, perhitungan siltation rate terpisah. Maka untuk memperoleh nilak keruk sebenarnya, hasil hitung volume dari AutoCAD Civil 3D 2016 ditambah dengan nilai siltation rate.

\section{Perhitungan Volume Keruk}

Metode perhitungan volume keruk yang digunakan adalah metode Grading dengan TIN (Triangulated Irregular Network) menggunakan perangkat lunak AutoCAD Civil 3D 2016. Secara sederhana penentuan volume pengerukan merupakan hasil dari komparasi data eksisting dengan data desain dimana data desain akan memotong data eksisting yang akan menghasilkan volume keruk. Model batimetri yang terletak di atas model desain keruk maka artinya ada galian / cut dan sebaliknya, apabila model bathymetri terletak di bawah model desain maka artinya ada timbunan / fill.

Interpolasi TIN membangun sebuah permukaan digital dari sekumpulan titik - titik data yang terdistribusi secara tidak teratur lalu dihubungkan oleh garis sehingga membentuk segitiga. Yang mana pada penelitian ini, titik titik data tersebut merupakan titik titik fiks perum hasil survey lapangan. Data titik fiks perum survey lapangan yang sudah diinterpolasi TIN dapat ditunjukkan melalui Gambar 3.
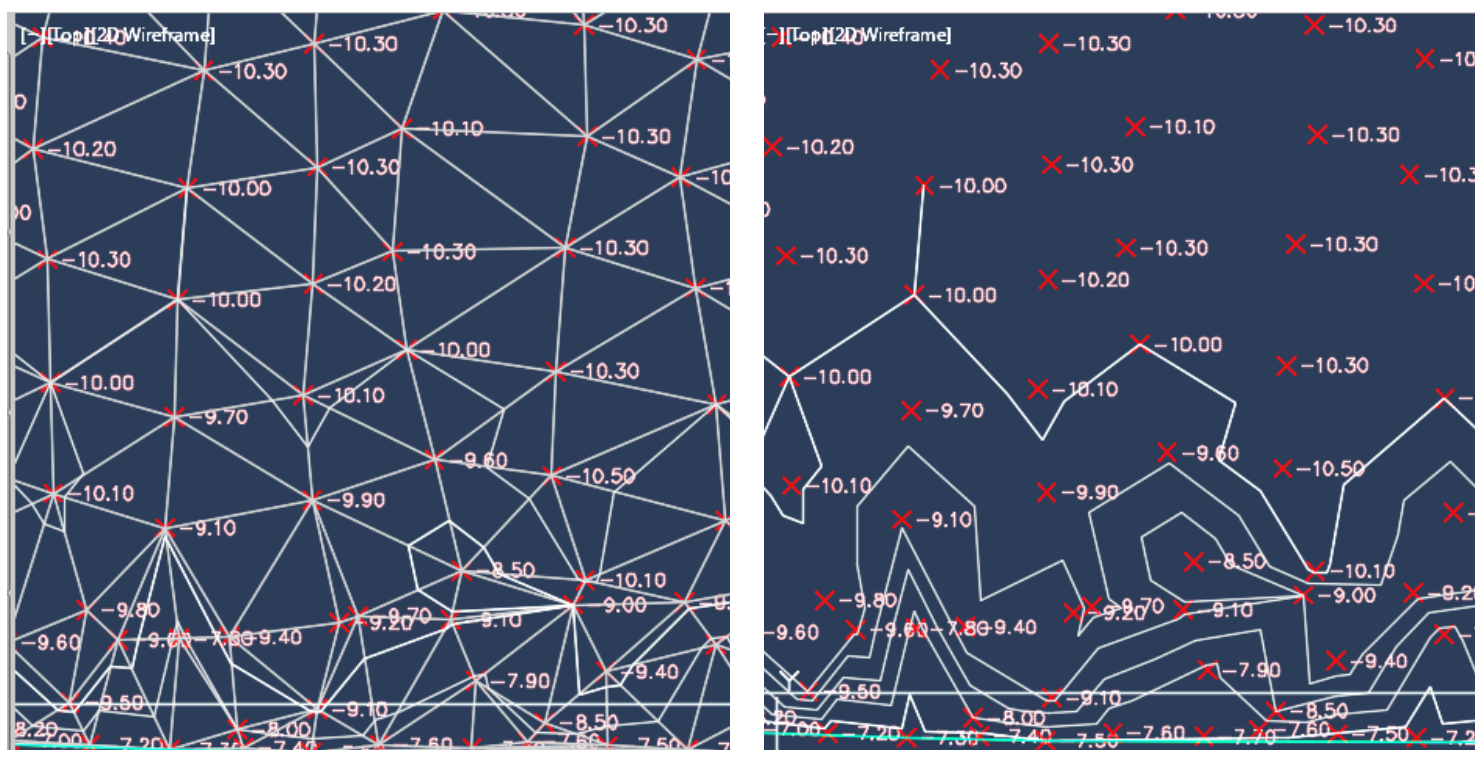

Gambar 3. Ilustrasi interpolasi TIN (Triangulated Irregular Network)

(Sumber : Survei Lapangan, 2019)

Segitiga segitiga tersebut membentuk prisma dengan batas bawah merupakan permukaan area keruk dan batas atas merupakan permukaan kontur. Batas atas dan batas bawah tersebut masing masing memiliki elevasi. Batas bawah memiliki elevasi kedalaman rencana sesuai standar aman kapal, sedangkan batas atas merupakan elevasi hasil pemeruman yang sudah dikoreksi. Sehingga diperoleh nilai selisih elevasi yang kemudian menjadi satuan perhitungan volume. 
HASIL \& PEMBAHASAN

Pasang Surut Sesaat

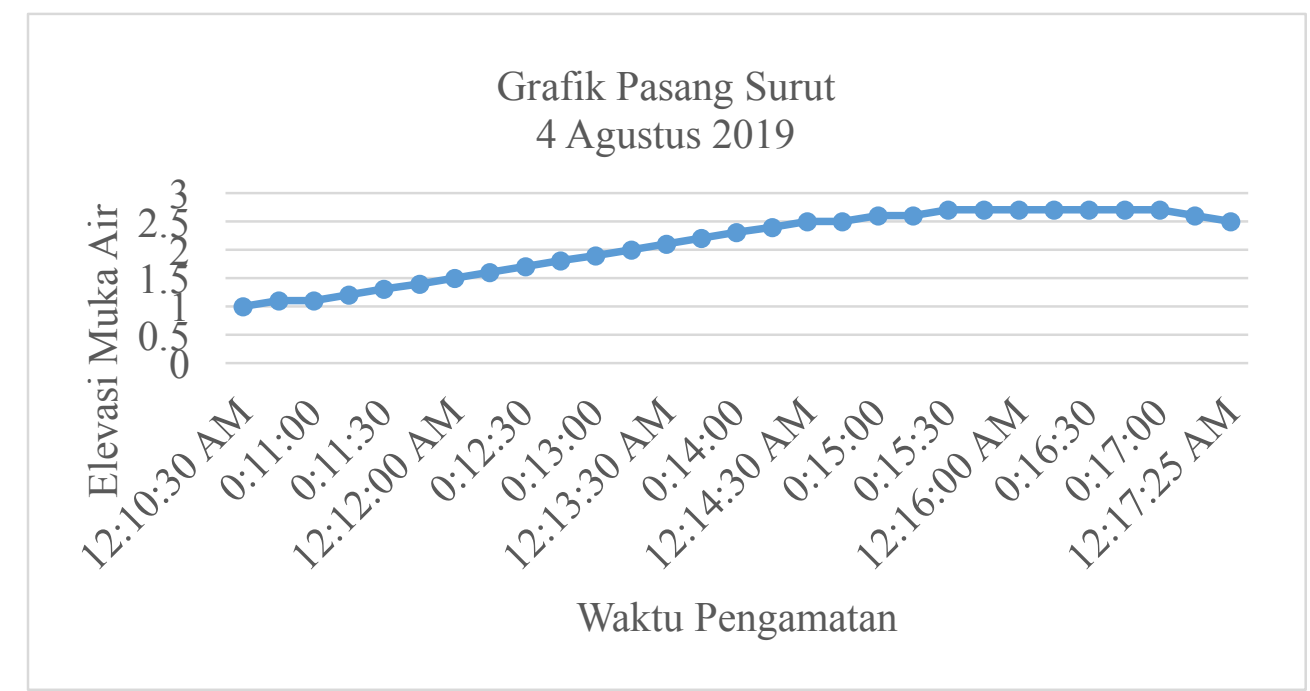

Gambar 4. Grafik Pasang Surut Terminal Peti Kemas Pelabuhan Belawan yang sudah dikoreksi (Sumber: Survei Lapangan, 2019)

Pengukuran data pengamatan pasang surut yang diambil tiap 15 menit menghasilkan nilai elevasi yang diambil pada waktu 10.30 sampai 17.25. Waktu tersebut adalah waktu yang diperlukan saat pemeruman di seluruh area perum. Data pemeruman tersebut direduksi terhadap data pengamatan pasut dengan referensi vertikal terhadap LWS pengamatan pasut. Pada data pengukuran survey batimetri, data fiks perum atau kedalaman diambil setiap 1 detik, sedangkan dalam pengamatan pasut data diamati setiap interval 15 menit. Sehingga untuk mengoreksi data kedalaman menggunakan interpolasi dengan data tinggi pasut. Dalam hal ini, digunakan interpolasi data pasut dari setiap interval per-15 menit menjadi interval per detik. Pengolahan data ini dilakukan dalam bentuk tabel sehingga hasil akhir yang diperoleh adalah kedalaman yang mengacu pada chart datum (LWS).

Perbedaan tinggi air pada saat pasang tertinggi dan surut terendah bernilai $1.7 \mathrm{~m}$ LWS. Perbedaan tinggi ini perlu diperhatikan oleh kapal yang akan memasuki pelabuhan. Untuk kapal dengan draft di atas $9 \mathrm{~m}$ LWS sebaiknya masuk ke pelabuhan pada saat air pasang. Hal ini dikarenakan pada saat pasang, kondisi purnama gaya tarik bulan dan matahari mencapai maksimum sehingga selain menyebabkan muka air laut mengalami kenaikan tertinggi, juga mengakibatkan kecepatan pergerakan arus yang disebabkan oleh pasang surut semakin besar. Jika pergerakan arus pasang surut yang membawa sedimen semakin besar, maka menyebabkan waktu lama sedimen untuk mengendap. Oleh karena itu, peta batimetri terbaru dan data pasang surut sangat perlu dimiliki oleh nakhoda kapal, karena kedua data ini dapat memandu kapal sewaktu melewati alur.

\section{Batimetri}


Hasil batimetri kolam pelabuhan peti kemas Pelabuhan divisualisasikan menggunakan perangkat lunak AutoCAD Civil 3D 2016 dan ArcGIS 10.4 Peta batimetri yang dihasilkan perangkat lunak AutoCAD Civil 3D 2016 berupa nilai kedalaman datum vertikal titik fiks perum. Sebenarnya aplikasi ini dapat memvisualisasikan garis garis kontur namun pada penelitian ini, untuk memperoleh informasi kerapatan garis garis kontur kedalaman dibuat menggunakan perangkat lunak ArcGIS 10.4.

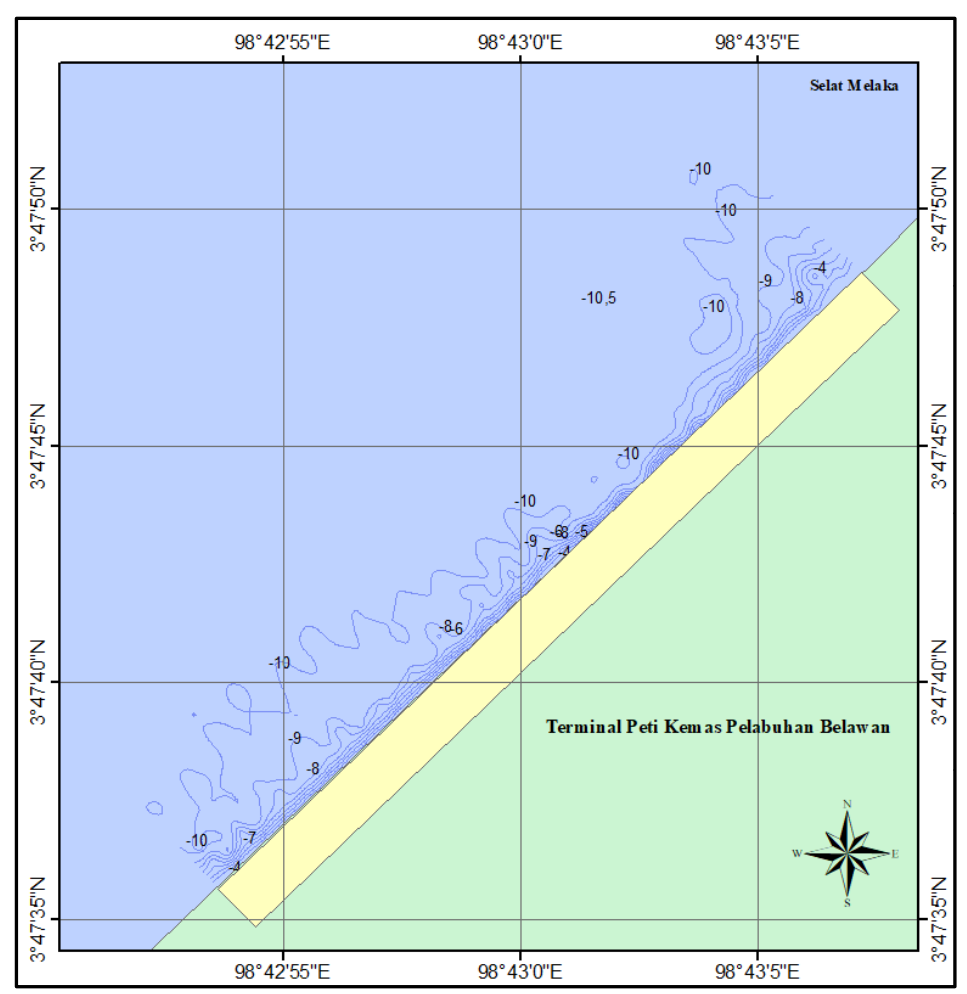

Gambar 5. Peta Kerapatan Garis Kontur Kedalaman Kolam pelabuhan Peti Kemas Pelabuhan Belawan (Sumber: Pengolahan Data Lapangan, 2019)

Perbedaan hasil peta batimetri di kedua perangkat lunak tersebut, terlihat dari variasi kedalaman. Peta batimetri hasil AutoCAD Civil 3D 2016 memiliki rentang kedalaman yang lebih bervariasi dibandingkan peta batimetri ArcGIS 10.4 karena merupakan persebaran kedalaman asli titik titik fiks hasil pemeruman yang sudah dikoreksi. Oleh karena itu dari segi datum vertikal, peta batimetri hasil AutoCAD Civil 3D 2016 lebih detail dan akurat karena merupakan hasil masukan nilai titik fiks perum sehingga lebih bisa digunakan untuk analisa volume pengerukan. Sedangkan peta batimetri hasil ArcGIS 10.4 merupakan kedalaman representatif, lebih bisa digunakan untuk analisa topografi di bawah laut. Dengan begitu, kedua perangkat lunak tersebut saling melengkapi akan infomasi batimetri. 
Hasil titik fiks pemeruman berupa titik-titik yang sangat rapat dengan interval jarak tiap titik kedalaman terhadap titik kedalaman lain yaitu $10 \mathrm{~m}$. Melalui peta kontur kedalaman (Gambar 5.) terdapat beberapa kedalaman perairan pada saat muka air laut surut terendah (LWS). Berdasarkan garis kontur yang ditampilkan secara 2 dimensi dengan interval $1 \mathrm{~m}$ diwakili dengan kedalaman $-4 \mathrm{mLWS}$ -10 mLWS. Berdasarkan garis kontur yang ditampilkan secara 2 dimensi, terdapat bentukan daratan yang menjorok ke laut atau membentuk daratan yang horizontal dengan dermaga. Yang mana menurut (Dewi, 2015) bentuk profil dasar laut seperti ini dinamakan spit atau lidah pasir. Kedalaman terdalam didapatkan pada daerah mengarah ke lepas pantai hal ini dikarenakan kedalaman yang terbentuk di wilayah di luar kolam pelabuhan dikhususkan untuk pengamanan lajur pelayaran kapal yang ditandai dengan pembatas berupa buoy, dimana buoy adalah alat bantu pelayaran yang diangker pada suatu tempat yang dianggap tepat, dan diberi tanda berupa lampu, radar pemantul atau bel/bunyi peringatan yang disesuaikan dengan penggunanya (Triatmodjo, 2009). Nugraha dan Subiyanto (2014) menambahkan dalam studi pengerukan, hasil pengukuran batimetri tersebut dikorelasikan dengan syarat aman draft kapal. Oleh karena itu, berdasarkan syarat aman draft kapal penelitian ini yang bernilai -11 $\mathrm{m}$ LWS, kedalaman dengan nilai -4 m LWS - -10.5 m LWS inilah yang menyebabkan kapal kandas saat bersandar maka pada kedalaman tersebut harus dikeruk sehingga kapal peti kemas dapat lewat dengan aman.

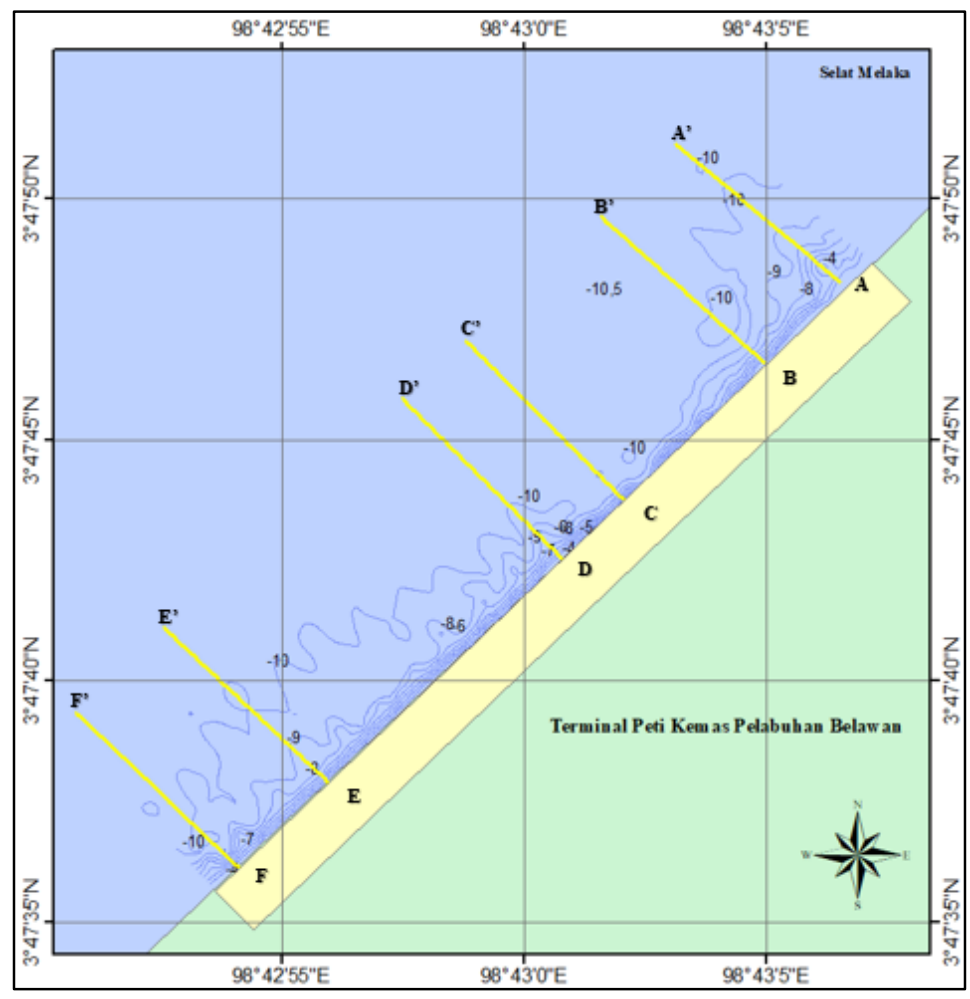

Gambar 6. Peta "Section Line" Penampang Melintang Kolam Pelabuhan Peti Kemas Kemas Pelabuhan Belawan (Sumber: Pengolahan Data Lapangan, 2019)

Untuk menunjukkan adanya kontra antara profil kedalaman eksisting dengan desain kedalaman rencana dibuat penampang melintang. Pembagian garis pembagian penampang melintang (garis penampang melintang A-A', B-B', C-C', D-D', E-E' dan F-F') dapat dilihat pada Gambar 6. 

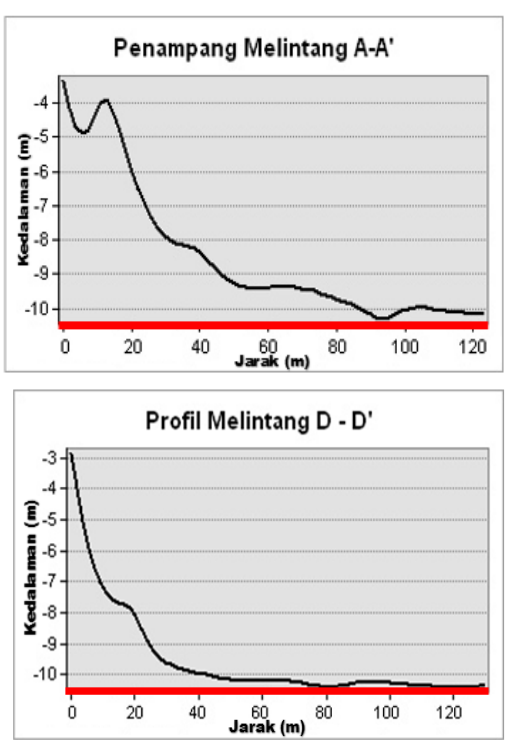
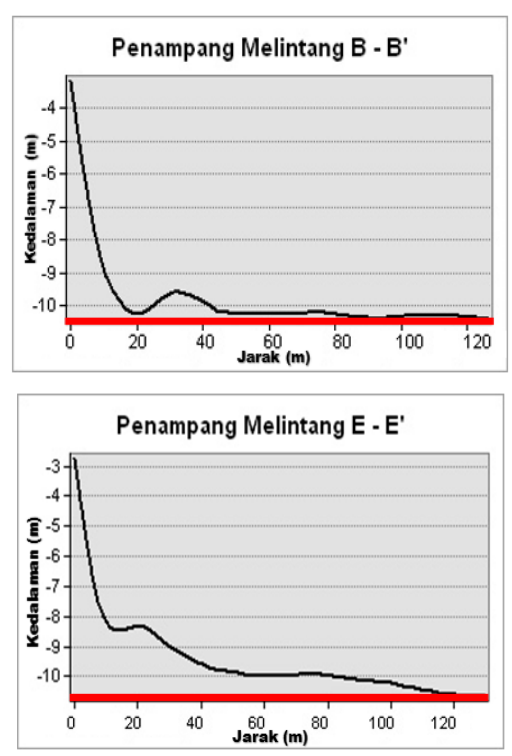
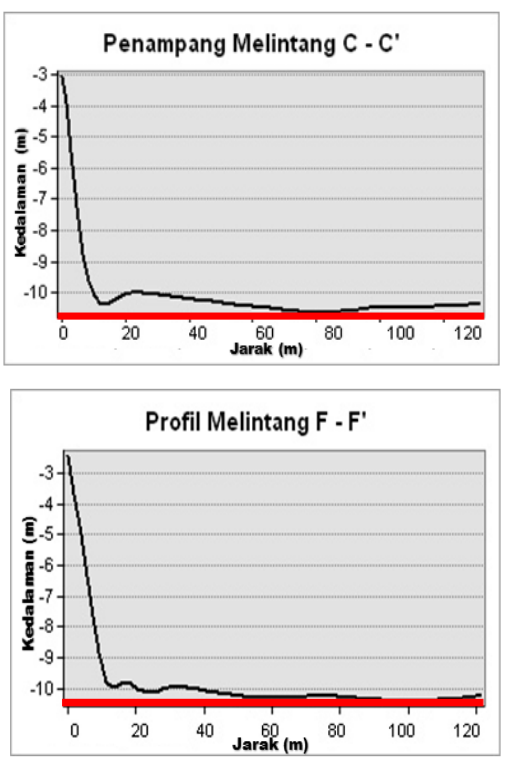

Gambar 7. Penampang Melintang A - A' - F - F' Morfologi Dasar Laut Terminal Peti Kemas Pelabuhan Belawan (Sumber: Pengolahan Data Lapangan, 2019)

Gambar penampang melintang pada area pengerukan bertujuan untuk menggambarkan kondisi profil kedalaman pada area pengerukan terhadap desain keruk serta sebagai acuan saat pelaksanaan pekerjaan pengerukan. Gambar penampang melintang pada area pengerukan menunjukkan adanya kontra antara profil kedalaman eksisting dengan desain keruk. Garis merah merupakan garis kedalaman minimal (dredging design) dimana bagian kontur yang berada di atasnya merupakan bagian yang harus dikeruk. Hasil menunjukkan bahwa kedalaman perairan masih belum sesuai dengan kedalaman rencana yang diinginkan diakibatkan adanya pendangkalan. Pendangkalan pada penampang melintang A-A' disebabkan oleh longsoran sedimen di luar area keruk yang memiliki kedalaman sekitar $7-9 \mathrm{~m}$ (Nurzanah, 2019). Sedangkan pendangkalan yang terjadi di area sebelah barat dermaga (E - E' dan F - F') diakibatkan adanya pasokan sedimen dari muara sungai serta aktivitas manuver kapal yang menimbulkan arus menyebabkan sedimen berpindah saat pasang dan mengendap saat surut.

\section{Kecepatan Arus}

Data kecepatan arus pada penelitian ini merupakan data pendukung pada laporan Pelindo I yang menunjukkan data kecepatan arus di perairan pelabuhan Belawan. Dari data tersebut menunjukkan kecepatan arus di stasiun pengamatan yang dilaporkan oleh Pelindo I, dimana kecepatan maksimum = $0,42 \mathrm{~m} /$ detik, kecepatan minimum $=0.21 \mathrm{~m} /$ detik dan kecepatan rata-rata $=0,28 \mathrm{~m} /$ detik .

\section{Desain Keruk}

Desain keruk kolam pelabuhan ditentukan dengan mengetahui draft kapal maksimum. Mengacu pada tabel karakteristik kapal (Tabel 1.), draft kapal maksimum adalah -9.8 m LWS yaitu kapal MOROTAI. Oleh karena itu, sesuai perhitungan Direkorat Jenderal Perhubungan Laut (2006), draft kapal yang aman adalah -11 m LWS. Kemudian untuk slope (kemiringan), mengacu pada klasifikasi kemiringan (Tabel 2.) yang ditentukan berdasarkan jenis sedimen. 
Berdasarkan studi terdahulu diketahui tipikal lapisan tanah dapat dilihat pada Gambar 8. Dapat diidentifikasikan bahwa kedalaman rencana -11 mLWS memiliki jenis sedimen lempung berlanau yang lembut (soft silty clay) menjadi lebih lembut seiring dengan bertambahnya kedalaman. Oleh karena itu, slope (kemiringan) yang digunakan adalah $1: 5$.

Gambar 8. Tipikal Borlog Tanah di Pelabuhan

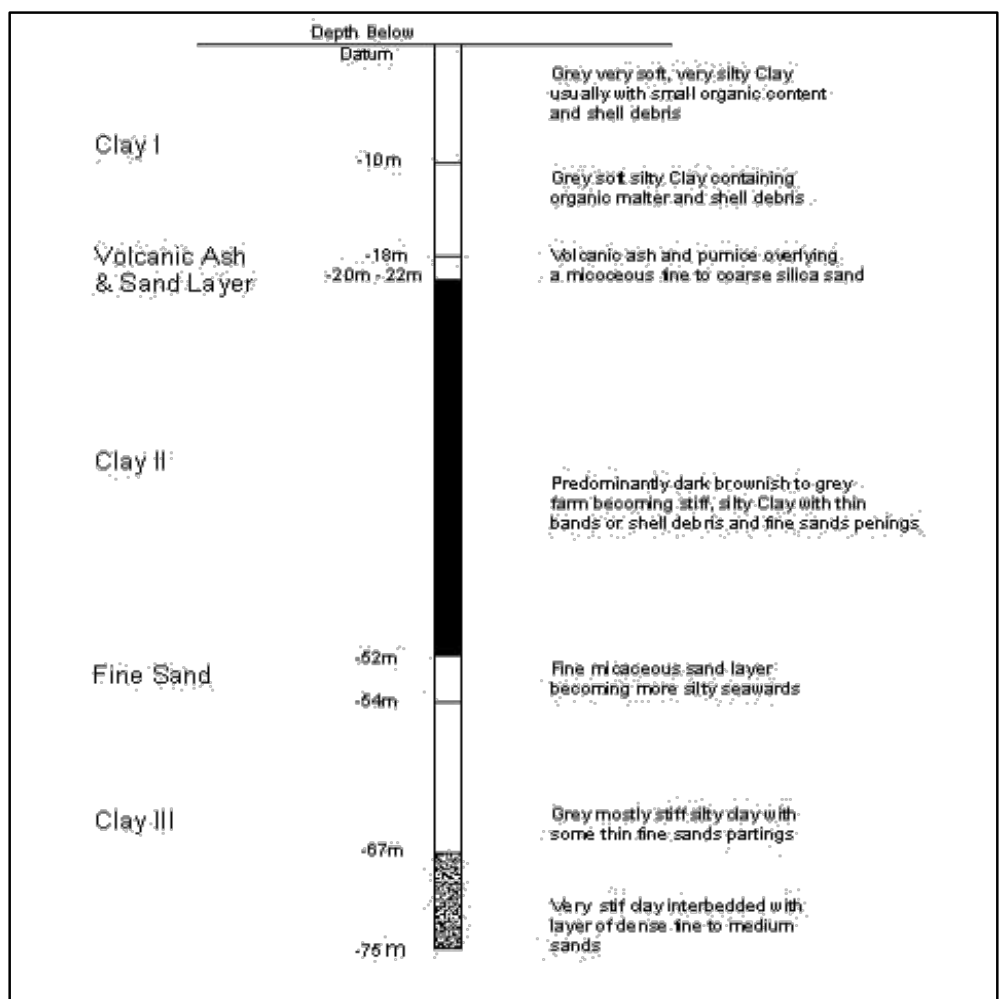

Belawan (Sumber: Pelindo, 2003)

Kemudian dengan metode grading, menghasilkan dua layer yaitu desain keruk berwarna jingga dan kedalaman eksisting yakni titik titik hasil pemeruman berwarna merah yang dapat dilihat pada Gambar 9.

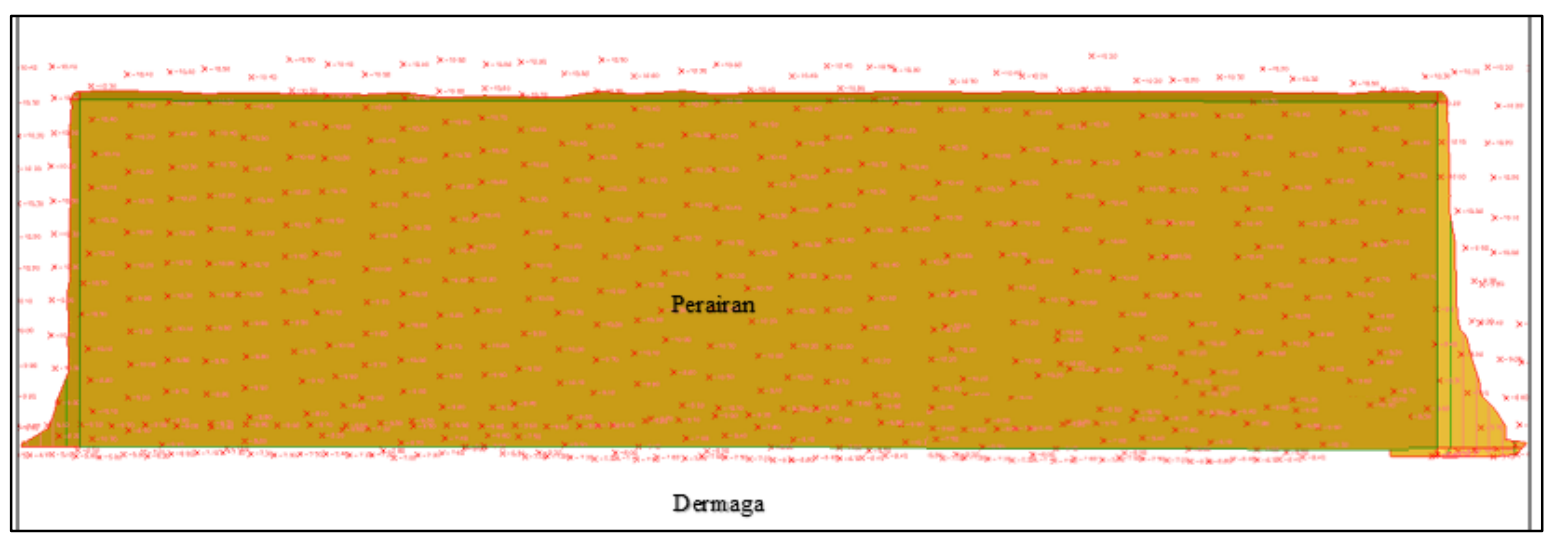

Gambar 9. Desain Keruk Atas

(Sumber: Pengolahan Data Lapangan, 2019) 
Desain terdiri dari dasar dan kelerengan. Bagian dasar yang merupakan batas bawah kedalaman rencana -11 m LWS berwarna hijau, sedangkan kelerengan berwarna merah. Desain keruk ini memiliki bagian kelerengan disekitar kiri dan kanan, jadi pada saat proses pengerukan maka kapal keruk berproses seperti desain yang dibuat. Tujuan dari dibuatnya bagian kelerengan pada saat pengerukan adalah untuk mengurangi dampak longsor pada saat melakukan teknis pengerukan sehingga menurut Huibert (2006) membentuk seperti trapezium terbalik.

Terlihat titik titik fiks pemeruman yang berwarna merah dan luasan berwarna jingga yang merupakan desain keruk. Pemeruman dilakukan lebih luas dari desain keruk untuk mengetahui kedalaman di sekitar desain keruk serta menjadi data untuk perangkat lunak AutoCAD Civil 3D 2016 melakukan perhitungan kelerengan. Kelerengan desain keruk bagian barat lebih landai karena terhubung dengan Dermaga Citra yang memiliki kedalaman yang hampir sama, sedangkan kelerengan desain keruk bagian timur sedikit curam karena berbatasan dengan kedalaman perairan belawan yang sebenarnya sebelum direncanakan pembangunan pelabuhan. Dibagian Selatan tidak terdapat kelerengan dikarenakan langsung berbatasan dengan dermaga. Dimana pendangkalan disekitar tembok dermaga akan dikeruk habis sesuai kedalaman rencana dikarenakan merupakan tempat kapal akan berlabuh untuk melakukan bongkar muat.

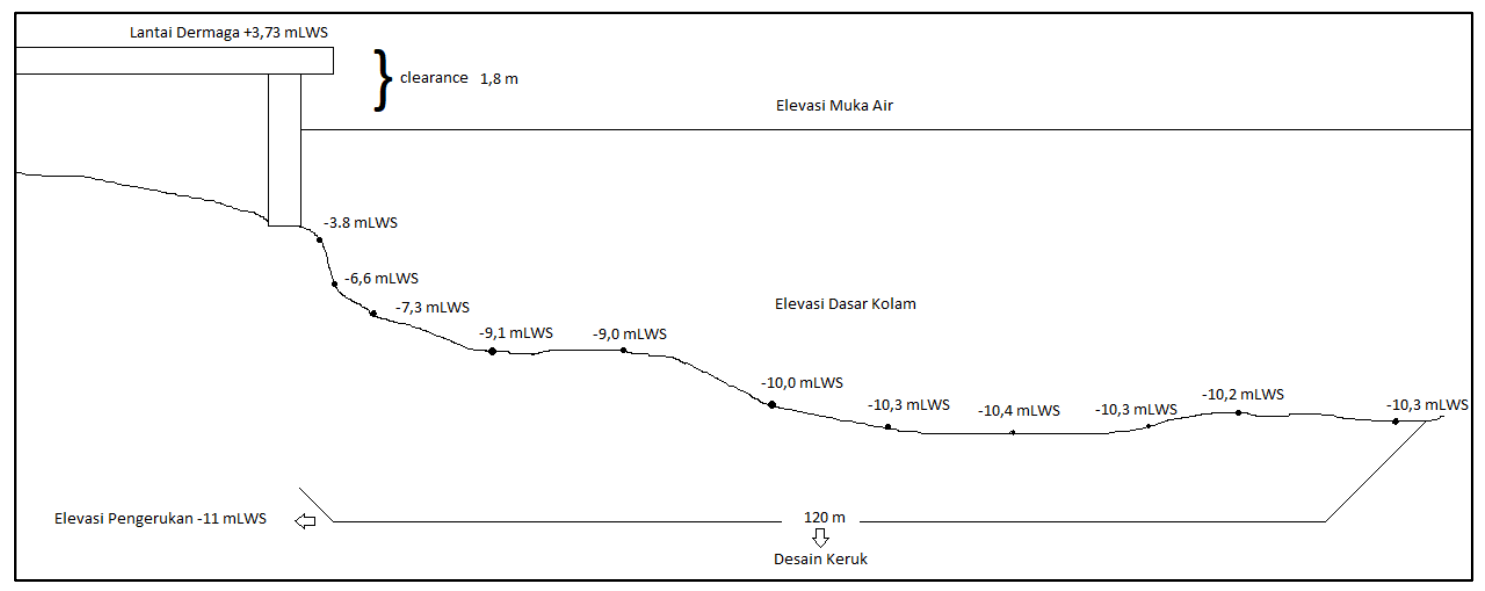

Gambar 10. Sketsa Denah Lokasi Keruk (Sumber: Pengolahan Data Lapangan, 2019)

Sketsa pada Gambar 10. di atas merupakan representasi dari daerah yang akan dikeruk. Berdasarkan sketsa di atas, terdapat desain lantai dermaga, hal tersebut mempengaruhi nilai pasang surut untuk menentukan elevasi rencana. Pada penelitian ini, elevasi muka air pasang surut rencana yang digunakan ialah LWS. Lws tersebut menjadi dasar acuan untuk pengambilan data kedalaman di area kolam pelabuhan setelah dikaitkan dengan benchmark. Benchmark tersebut sudah terdapat nilai mutlak elevasi lantai dermaga yaitu 3,73 mLWS yang menjadi acuan dalam koreksi kedalaman. Hal ini dikarenakan menyangkut pada pengambilan data pasang surut lapangan yang mengambil data berupa jarak dari lantai dermaga ke muka air atau bisa dikatakan clearance pada sketsa tersebut. Kemudian nilai jarak tersebut dikaitkan dengan nilai elevasi lantai dermaga sehingga terdapat selisih, yang pada penelitian ini disebut Koreksi BM. Selisih atau Koreksi BM itulah yang digunakan untuk mengkoreksi atau mengubah kedalaman mentah hasil perum yang masih dalam satuan $\mathrm{m}$ (meter) agar menjadi mLWS. Ketika nilai tersebut sudah menjadi mLWS maka nilai tersebut dapat disesuaikan dengan SOP kolam pelabuhan untuk menentukan nilai kedalaman pada saat surut terendah. 


\section{Perhitungan Volume Keruk}

Volume keruk dapat dihitung setelah proses Grading yakni penyatuan antara model pada desain keruk dan model batimetri / existing sudah diproses ditandai dengan warna hijau pada Gambar 11.

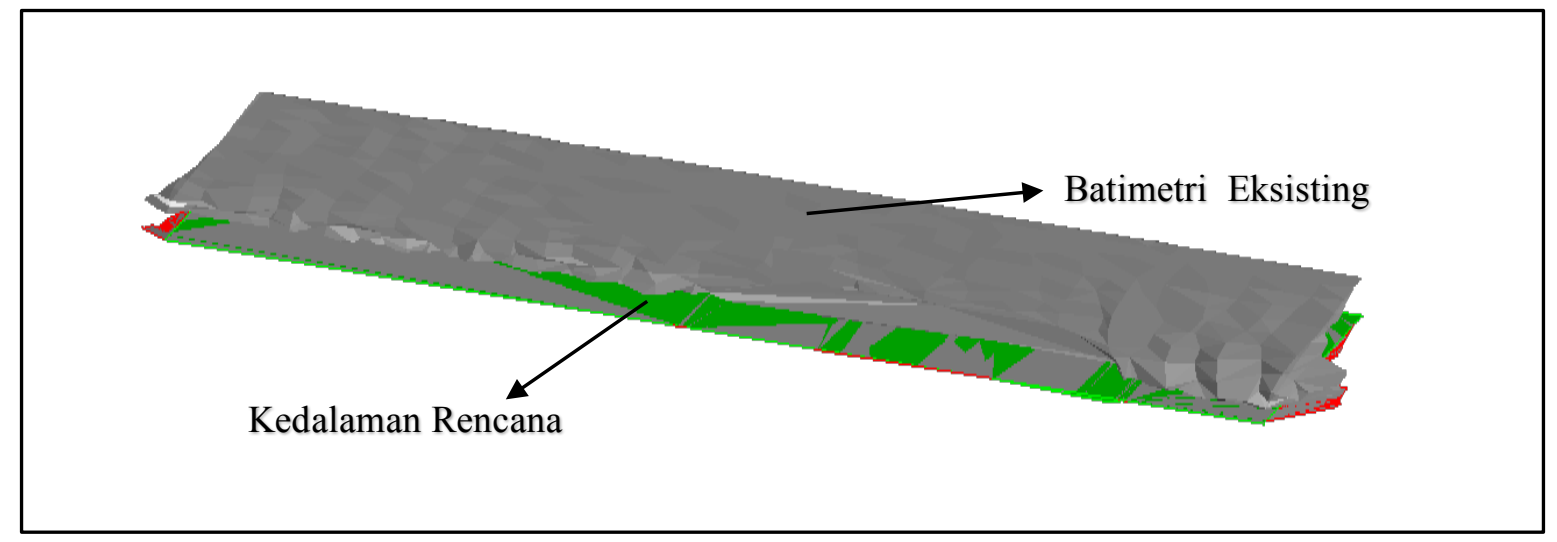

Gambar 11. Sketsa Hasil Grading

(Sumber : Pengolahan Data Lapangan, 2019)

Melalui gambar tersebut terlihat bahwa kedalaman eksisting sudah tidak sesuai dengan syarat aman kapal sebagaimana ditunjukkan pada desain keruk, sehingga kolam pelabuhan harus dikeruk dan dihitung volumenya. Setelah di grading, perhitungan akan terfokus pada area yang sudah di grading. Kemudian terdapat opsi Cut/Fill pada grading untuk menghitung volume pengerukan. Perhitungan volume keruk dilakukan menggunakan perangkat lunak AutoCAD Civil 3D 2016 dengen metode TIN (Triangular Irregular Network). Perhitungan volume keruk dihitung dari total volume jaring jaring segitiga yang membentuk suatu geometri prisma terhadap dasar perairan. Ale (2012) menyatakan volume prisma dihitung dengan mengalikan permukaan proyeksi dengan jarak antara pusat massa dari dua segitiga yaitu desain surface dan base surface.

\section{Gambar 12.}

Melalui desain keruk, dihasilkan volume kolam pelabuhan yang harus dikeruk dapat dilihat pada

\begin{tabular}{|l|l|}
\hline Statistics & Value \\
\hline $\begin{array}{l}\text { General } \\
\text { TIN }\end{array}$ & \\
\hline Number of triangles & 8027 \\
\hline Maximum triangle area & $2075.34 \mathrm{sq} . \mathrm{m}$ \\
\hline Minimum triangle area & $0.00 \mathrm{sq} \cdot \mathrm{m}$ \\
\hline Minimum triangle length & $0.000 \mathrm{~m}$ \\
\hline Maximum triangle length & $152.784 \mathrm{~m}$ \\
\hline Volume & \\
\hline Base Surface & EG \\
\hline Comparison Surface & sitegrading \\
\hline Cut Factor & 1.000 \\
\hline Fill Factor & 1.300 \\
\hline Cut volume (adjusted) & $87330.94 \mathrm{Cu} . \mathrm{M}$. \\
\hline Fill volume (adjusted) & $7.92 \mathrm{Cu} . \mathrm{M}$. \\
\hline
\end{tabular}

Gambar 12. Hasil Perhitungan Volume Pengerukan Kolam pelabuhan Peti Kemas Pelabuhan Belawan dengan Software AutoCAD Civil 3D 2016

(Sumber: Survei Lapangan, 2019). 
Hasil perhitungan volume pengerukan pada Gambar 12. belum ditambahkan siltation rate. Maka hasil volume pengerukan (Cut Volume (adjusted)) tersebut harus ditambah nilai siltation rate sebagaimana berdasarkan Staff Direktorat Teknik PT. Pelindo 1, nilai siltation rate Pelabuhan Belawan sebesar $10 \%$.

Siltation rate $=10 \% \times$ (volume pengerukan hasil pengolahan data dengan Software

AutoCAD Civil 3D 20162016 (Cut Volume (adjusted))

$=10 \% \times 87.330,94 \mathrm{~m}^{3}$

$=8.733,094 \mathrm{~m}^{3}$

Volume Pengerukan Total = Volume pengerukan hasil pengolahan data dengan

Software AutoCAD Civil 3D 2016 (Cut Volume (adjusted)) + Siltation rate

$=87.330,94 \mathrm{~m}^{3}+8.733,094 \mathrm{~m}^{3}$

$=96.064,034 \mathrm{~m}^{3}$

Perhitungan volume menggunakan AutoCAD Civil 3D 2016 dengan menambahkan nilai siltation rate $10 \%$ didapatkan nilai sebesar $96.064,034 \mathrm{~m}^{3}$. Jika dikorelasikan dengan kedalaman rencana, volume yang dikeruk tersebut meliputi keseluruhan area keruk. Pada perhitungan juga terdapat fill volume yang menandakan terdapat kedalaman yang lebih dalam dari -11 m LWS, maka kedalaman tersebut ditimbun tanah agar sesuai dengan desain -11 m LWS. Namun, menurut Staff Direktorat Teknik PT. Pelindo 1, hal ini tidak perlu dipertimbangkan.

Berdasarkan hasil perhitungan tersebut dapat diketahui bahwa terjadi perubahan kedalaman terhadap kedalaman rencana yang merupakan pendangkalan. Pendangkalan ini merupakan material sedimen yang terendapkan atau disebut juga mengalami sedimentasi. Sedimentasi di Pelabuhan Belawan terjadi karena pasokan sedimen Sungai Belawan dan Sungai Deli. Pasokan sedimen kemudian terbawa oleh arus sungai dengan kecepatan tertentu lalu menuju ke pelabuhan (Nurzanah, 2019). Sedangkan pada area pelabuhan, Iskandar (2009) menambahkan bahwa arus sudah dipengaruhi oleh pasang surut. Arus pasang surut ini akan mempengaruhi kecepatan jatuhnya pasokan sedimen, dimana sedimen akan jatuh sesuai dengan gaya gravitasi saat air tenang dan akan mengalami perpindahan jatuh karena adanya arus.

Menurut Febriyanti et al (2018), perairan dengan kecepatan arus $0.1-0.8 \mathrm{~m} / \mathrm{s}$ tergolong lemah. Nybakken (1992) dalam Pamuji et al., (2015), menambahkan bahwa jika kecepatan arus lemah maka partikel yang mengendap adalah partikel partikel debu dan liat (clay). Hal ini sesuai dengan Pelabuhan belawan yang memiliki kecepatan arus pada saat tertinggi yaitu mencapai $0.4 \mathrm{~m} / \mathrm{dtk}$ dan terendah 0.2 $\mathrm{m} / \mathrm{dtk}$ yang mana menurut Febriyanti et al (2018) tergolong lemah. Kecepatan arus ini pun membawa jenis material sedimen berupa lapisan lempung berlanau lembut (soft silty clay). Oleh karena itu, hal inilah yang mendukung kerap terjadi pengendapan sedimen yang mengakibatkan pendangkalan pada lokasi ini. Pendangkalan pada lokasi disebabkan oleh arus yang lemah, maka mempermudah sedimen berjenis lempung lembut pada lokasi tersebut berpindah lalu mengendap. Hal ini sesuai dengan pernyataan Fernedy (2008) yang menyatakan bahwa perairan dengan arus yang lemah akan mengendapkan partikel lumpur halus sebaliknya bahwa perairan dengan arus yang kuat akan mengendapkan partikel dengan ukuran besar.

\section{KESIMPULAN}

Berdasarkan hasil penelitian yang telah diperoleh, dapat diambil kesimpulan sebagai berikut:

1. Dari hasil pemeruman, menunjukkan bahwa nilai kedalaman pada area keruk kolam pelabuhan berkisar antara -3,70 m hingga -10,5 m terhadap Low Water Spring (LWS).

2. Desain kedalaman rencana kolam pelabuhan berdasarkan nilai draft kapal terbesar yaitu $-11 \mathrm{~m}$ terhadap LWS.

3. Didapatkan volume pengerukan pada kolam pelabuhan peti kemas Belawan Sumatera Utara yang memiliki panjang sebesar $567 \mathrm{~m}$ dan lebar sebesar $120 \mathrm{~m}$ ialah $96.064,034 \mathrm{~m}^{3}$. 


\section{DAFTAR PUSTAKA}

Defrimilsa. 2003. Studi Perbandingan Profil Batimetri Perairan Utara Belitung Hasil Deteksi Sistem Akustik Bim Terbagi Simrad EY500 Dengan Profil Batimetri Peta Dishidros TNI-AL [Skripsi]. Bogor: Institut Pertanian Bogor.

Dewi, L. S., Ismanto, A., \& Indrayanti, E. 2015. Pemetaan batimetri menggunakan single-beam echosounder di perairan Lembar, Lombok Barat, Nusa Tenggara Barat. Journal of Oceanography, 4(1), 10-17

Direktorat Jenderal Perhubungan Laut. 2006. Pedoman Teknis Kegiatan Pengerukan dan Reklamasi. Kementerian Perhubungan Republik Indonesia, Jakarta.

Dwi, G. M., \& Tutuko, B. 2017. Analisis Penerapan Sistem Manajemen Keselamatan dan Kesehatan Kerja (SMK3) dalam Proyek Pembangunan Pelabuhan di Kabupaten Kendal. Teknika, 12(2).

Febriyanti, L., Purnomo, P. W., \& A'in, C. (2018). Karakteristik Oseanografi Dan Sedimentasi Di Perairan Tererosi Desa Bedono, Demak Pada Musim Barat (Characteristics Of Oceanography And Sedimentation of Waters Erosion In Bedono Village Demak During West Season). Management of Aquatic Resources Journal, 6(4), 367-375.

Fernedy, F. 2008. Struktur Komunitas Makrozoobenthos di Muara Sungai Teluk Jakarta. (Skripsi). Program studi Ilmu Kelautan dan Teknologi Kelautan, Fakultas Perikanan dan Ilmu Kalautan, Institut Pertanian Bogor. Bogor. 64hlm.

Geodis, Ale. 2012, Calculation of Volume, Diakses pada 05 Januari 2020, dari http://www.geodisale.com.

Huibert, J.L. 2006. Handbook of Offshore Surveying-Volume Two: Acquisition and Processing. Skilltrade, Amsterdam, $326 \mathrm{p}$.

Iskandar, I. W. P. (2008). Studi Karakteristik Sedimen di Perairan Pelabuhan Belawan.

Laporan Survei PT. PELINDO I (2019). Pemeliharaan Alur dan Kolam Pelabuhan PT. Pelindo I (persero). PT. Pelindo I (persero), Sumatera Utara

Nurzanah, W. (2019). Penentuan Lokasi Pembuangan Material Keruk Alur Pelayaran Pelabuhan Belawan Dengan Sistem Informasi Geografis. Buletin Utama Teknik, 14(2), $80-91$.

Nybakken, W.J., 1988. Biologi Laut Suatu Pendekatan Ekologis. Gramedia, Jakarta.

Pamuji, A., M. R. Muskananfola, C. A’in. 2015. Pengaruh Sedimentasi Terhadap Kelimpahan Makrozoobenthos Di Muara Sungai Betahwalang Kabupaten Demak. Jurnal Saintek Perikanan. 10 (2): 129-135

Pelindo, 2003, Studi Perilaku Sedimentasi / Siltasi \& Coastal Morphology Dalam Rangka Pengembangan Pelabuhan Belawan, Penerbit PT. Pelabuhan Indonesia.

Poerbandono dan E. Djunarsjah. 2005. Survey Hidrografi. Refika Aditama.

Peraturan Menteri Perhubungan Republik Indonesia. 2013. Kebijakan, Norma, Standar, dan Prosedur Pelaksanaan Kewenangan Bidang Perhubungan Laut yang Dilimpahkan Kepada Dewn Kawasan Sabang. Kementerian Perhubungan Republik Indonesia, Jakarta.

Staff Direktorat Teknik PT. Pelindo I (persero). 2019. Petunjuk Teknis Pemeliharaan Alur dan Kolam Pelabuhan PT. Pelindo I (persero). PT. Pelindo I (persero), Sumatera Utara

Surakhmad, W. 1980. Pengantar Penelitian Ilmiah. Tarsito, Bandung.

Yudianto, A. C., Ismunarti, D. H., \& Indrayanti, E. (2014). Pemetaan Batimetri Kolam Pelabuhan Khusus PT. Arun Ngl, Lhokseumawe, Aceh. Journal of Oceanography, 3(3), 366-374. 